\title{
Curse Of The Desert? Magic Realism And The Pitfalls Of Setting In Bessie Head's Maru And Ben Okri's Starbook
}

\author{
Wazha Lopang \\ Department of English, University of Botswana
}

Received: 07-03-2014

Accepted: 27-04- 2014

Published: 01-07- 2014

doi:10.7575/aiac.ijclts.v.2n.3p.4

URL: http://dx.doi.org/10.7575/aiac.ijclts.v.2n.3p.4

\begin{abstract}
This paper argues that magic realism cannot evolve in a setting where there is no bush environment because this is where oral literature flourishes. The oral literature provides the conditions necessary for magic realism to explore the relationship between the surreal and the mundane. If the magic realism is set outside this bush environment then the experience becomes muted. Texts that have a clear dichotomy between the world of human habitation (such as villages, towns) and that of the spirits (such as the bush or forest) enable magic realism to evolve into a more profound experience, that of the dream setting. My argument is that the dream setting needs this dichotomy for it to exist. In essence, texts that do not use the bush environment as part of their setting fall short in their creative aspect because the space and time within which characters function are constrained. The use of the oral tradition with its interplay of the human, animal and spirit worlds creates a platform for the dream setting, something which cannot happen where the setting limits itself to the world of human habitation. I will compare Bessie Head's Maru with Ben Okri's Starbook to show how the oral tradition in the latter text makes it achieve a level of magic realism that cannot be possible in Head's Maru.
\end{abstract}

Keywords: Magic Realism, Oral Literature, Fantasy, Setting, Dream World

1. Introduction

African written literature has mapped itself on the literature world using the oral tradition. This use of orality is what writers like Chinua Achebe have used as justification for their writing in a European language, while dissenting voices of Ngugi wa Thiongo, Obi Wali and others were calling for a rejection of English as a medium of telling the African experience. Ashcroft, in The Empire Strikes Back, put it forward that "the crucial function of language as a medium of power demands that post colonial writing defines itself by seizing the language of the centre and re-placing it in a discourse fully adapted to the colonised place." (37). Though texts like Chinua Achebe's Things Fall Apart (1956) and Gabriel Okara's The Voice (1964) have shown how language can be manipulated to reflect the black man's cultural experience, magic realism goes beyond the dynamics of language to reveal through folklore those structures that underpin the ideology of a group of people.

There is a discernible link between the world of fantasy and oral literature and it is the possibilities raised by this link that differentiates the two texts I aim to analyse in this paper. Abiola Irele maintains that oral literature is a crucial reference point from which the African Imagination stems (10). So, despite the medium that African literature uses, orality is generally infused in the narrative style. For instance, the quest motif in the philosophical depiction of the African identity in Ayi Kwei Armah's Two Thousand Seasons (1973) suggests that African culture is fundamentally oral. As Newell states, "Armah oralizes his forms in a manner that seems to mask the strategic quality of his narrative choices and to assert an essential orality beyond, above, and behind all African unity." (67). It goes to show that when one talks of orality in general and magic realism in particular there is a sense of hybridity. Therefore the idea of exclusivity should be cautioned against. Woods states that "upholding the indigenous as a justification in itself for returning to ancient values and ancestors, without ironic distancing, is inimical to magic realism." (262). As Brenda Cooper maintains, a pivotal feature of magic realism is "its hybridity that contests boundaries and violates them." (49). Magic realism is thus about traversing boundaries between reality and fantasy and this undoubtedly affects the way in which the narrative is absorbed. Newell states that "if a boundary exists at all between oral and written texts, it does not relate to structure and form, but to the different ways in which these genres interact with their audiences." (73). So it is not simply a case of written literature finding its way into the oral arena or orality landing onto the printed page. These two mediums should not be seen as mutually exclusive and magic realism in a sense bridges the gap between what many would see as a clear dichotomy between the verbal and the literal.

However, it is apparent that the use of orality in African literature is more pronounced in certain aspects of the African region than the others. The reason for this is not so much that one region has a stronger oral tradition than the other. It is because the type of setting that is used allows the oral tradition in the written literature to evolve in a way that is not possible in other regions. Boccia sees things differently. He argues that magic realism, "is an international literature that oversteps national boundaries and language with roots in many literary traditions." (21). What this means is that a particular culture cannot have an exclusive footprint on magic realism. Essentially, magic realism can be found anywhere regardless of that society's traditions or its environmental conditions. This is a fair point but the way in which magic realism presents itself in Botswana and Nigeria differs precisely because of the peculiar traditions within those 
communities. The argument of this paper is that the bush setting provides a fertile springboard for magic realism and the lack of this setting forces a writer to explore an alternative means to narrate his/her experience. The present study aims to investigate why magic realism in Starbook is superior to that in Maru. This investigation is rooted in the premise that a setting that is devoid of a dichotomy between the human world and the spirit world is unable to produce a rich experience of magic realism. Magic realism needs this dichotomy for it to thrive.

\section{Temporal space and magic realism in Maru}

In Botswana, the arid landscape has meant that writers like Bessie Head explore other avenues of magic realism in their works. Bessie Head illustrates magic realism through the psychological sphere in that her characters are able to enter the souls of other characters through a mental channel. Maru (1971) is a tale about an abandoned young Mosarwa (bushman) girl who is brought up by a white lady who seeks to find out if formal education and a dose of European mannerisms will end prejudice towards the Basarwa. Maru, after whom the novel is named, is a chief of Dilepe village who competes for the mosarwa girl, named Margaret Cadmore after her foster mother, with Moleka, a close friend of his. Maru's character, for instance, manipulates the Mosarwa maiden Margaret Cadmore junior by influencing her visions. Anderson states that, "Head takes her readers on a literary journey that incorporates themes of mysticism and the ethereal nature of human existence and evolution. It is through interdependency, acceptance and love that the lives of the characters in Maru are transformed." (6). In Maru we have characters becoming a setting for magic realism. Consequently, the magic realism operates in a confined yet expansive sphere. In other words, the confined space of the body becomes through the mind an infinite arena where one's thoughts and actions can be manipulated. Maru does this to great effect in getting Margaret Cadmore to be his future wife, ultimately denying Moleka, his rival, from winning the Mosarwa's heart. The magic realism one sees in Maru is one that ensures the maiden is won over not through love but through scheming and underhanded tactics. In Maru the use of magic realism has circumvented the bush setting entirely. This means that the writer has been forced by the dictates of environment to use magic realism in a way that challenges conventional depictions of such in African literature. The use of the bush setting is not employed by Head chiefly because the writer does not have that option available to her.

Amos Tutuola's The Palm wine Drinkard showed how the forest could be presented as the exotic through which everything and anything is possible. The suspension of reality is already made possible by the reader's awareness that the forest represents a lack of civilisation and emits strong underlying tones of chaos and absurdity. It is a place where spirits roam and death lurks. As Lindfors states, Tutuola's tale is "a voyage of the imagination into a never-never land of magic, marvels and monsters." (55)The forest is always held as a counter to the relative cultural and social order of village life. In Maru we see how the mind is a substitute for the forest setting that is not available to Head. In other words, whereas the magic realism in Tutuola's work happens around the character in the bush he travels through, in Head's Maru, the magic realism happens within the mind of a character. The mind allows Maru to achieve his ambition of a humanity that is not affected by ethnic discrimination. The magic realism in Maru allows one to see that magic realism, regardless of its choice of setting shows the possibility of a better future than that currently experienced in the real world. With Maru Head has very few options regarding the physical setting. In other words, the village of Dilepe is an arid outpost that has none of the conditions necessary to see the type of magic realism that evolves into something more profound than what it is at first. The lack of the bush setting, with its connotations of the unknown, darkness and chaos, means that in her use of magic realism Head only employs the mind as a canvass through which characters communicate a deeper, philosophical awareness of existence. This is the awareness that it is possible to live in a society that operates on basic human rights of equality without subjugation or titles of chief and servant. Though it is tempting to argue that Bessie Head's use of magic realism in the way that she has suits the purpose of what she intended, one must adhere to the principal that the writer is not the final authority on such matters. The Intentional Fallacy posits that it is not advisable to rely on authors to give substantive interpretations of what they write about because when published such works become public and liable to be interpreted in whatever manner.

It is through magic realism - as shown through the mental communications Maru has - that the ideal socio-political solution is achieved. For Bessie Head then the absence of a forest setting is not necessarily a setback but it means that the options that a forest setting provides cannot be replicated. Does this mean therefore that this lack of the forest setting means that the magic realism that is used is not as rich as that which has this setting? In order to answer this one must first understand that in the oral tradition, out of which stories that inform and define the African image stem, storytelling has generally used culture as an expressive platform. What this means is that stories, whether they are set in a world away from the village boundaries or within the village itself, employ the surroundings to garnish a tale. The oral tradition with its myriad of tales becomes a foundation out of which the traditional African experience is revealed. In Maru the setting of Dilepe does not provide, physically, that which can enable the fantastical to thrive. There is nothing outside the village itself that can represent for the reader a sense of the 'other world' with all its implied mysteries. Head thus uses the mind as an alternative setting through which the unreal can gain some form of credence. Maru's mind becomes for Head a substitute for the lack of setting that one would find in the oral tradition. It is through the visions that Margaret Cadmore has that we see the future in the paintings that she does. This is the physical representations of Maru's utopia and from these drawings there is the final, concrete step of the house itself and the married couple that is foreshadowed at the beginning of the novel. Thus, in Maru the magic realism is such that it moves from the visions to the paintings to the reality. It is a three step process.

As Maru shows however, the expression of this type of magic realism is dependent on the character's life experiences. It cannot move beyond that or employ images outside the character's reality. In other words, the visions that Maru gives Margaret Cadmore do not feature settings outside what he knows to exist. It is a magic realism devoid of the fantastical in the manner that one sees in Okri's work. There are no demons, spirit women and so on. This is because in Maru, the 
village of Dilepe does not have these occurrences and so his visions cannot project what is not in his reality. The magic realism that Maru reveals in the visions he gives Margaret is one of paintings and feature physical structures and people of opposing cultures. Margaret reveals to her friend Dikeledi, who is also Maru's brother, the dreams she has been experiencing,

"I looked up again and a little way ahead I saw two people embrace each other. I stared quite hard because they were difficult to see. Their forms were black like the house and the sky but, again, they were surrounded by this yellow light. I felt so ashamed, thinking I had come across a secret which ought not to be disclosed." (Head, 99)

She is unaware that the two people in her dream are Maru and herself. Furthermore, the house that she sees is their future matrimonial house. Maru has infused visions into her unconscious self in order to prepare her for his plan of eloping with her so as to bring hope to the Basarwa who are still slaves of the powerful tribes. This is the secret that should not be revealed - the fact that a chief of a tribe is going to marry an outcast.

This is Maru's reality. In order for his vision of a society that is not defined by prejudice to bear fruit he has to infiltrate the dreams of Margaret and prepare her for what is going to happen. Magic realism builds on a given reality and expands on it. At the centre of magic realism there is a symbiotic relationship that is at play that one must acknowledge. Barhoun states that "magical realism subverts the traditional binary opposition between realism and fantasy, not by placing fantasy in a dominant position over realism...but by favouring multiplicity and holding both fantasy and realism in a state of equal existence." (91-92). Jackson underlines the point in stating that, the fantastic merges "elements of both the marvellous and the mimetic." (34). So there has to be some grounded reality in the world of magic realism and that reality is informed by the writer's own cultural experience. It must be understood that the magic realism that is shown in Maru is limited in terms of what Maru the character can project. The bush setting would have enabled the magic realism to be more enriching in scope and intent. The use of a bush setting allows the writer to use magic realism at different levels and the setting provides a richer cultural experience than what one would get in the magic realism where the mind becomes a platform for the surreal. In Maru the magic realism is one without the oral tradition. This more than anything greatly limits the way in which it can be manipulated by the writer. Without this other setting of the bush, with its spirits and fairies, the tribulations that characters go through in Maru is better explained through a magic realism that is grounded in the mind. For instance, Maru is confronted by his spy, Ranko, who reports that Margaret Cadmore is dying. She has just heard news that Moleka has impregnated Dikeledi. Maru remarks, "Is she sick, Ranko?" he said smiling. "Is she dying? Don't worry about that. Let her suffer a bit. It will teach her to appreciate other things." (Head, 116). By 'other things' Maru is commenting on how Margaret needs to reflect on Maru's vision of marrying across cultural divides and hence destroying the prejudice that underpins this society. The only way Margaret can get this insight, according to Maru, is to suffer an emotional form of paralysis. Maru uses magic realism in a punitive manner. He knows, unlike Ranko, that the cause of the woman's grief is a broken heart. There is no empathy just a cold deduction of events. When he does approach her, what he offers is not understanding or love but a statement that displays his vindictive nature, "It's not an ailment you die of. Sometimes you recover in a moment, especially when the cause of it is a worthless man like Moleka." (Head, 118). Soon after this episode he leaves the village with her to start a new life.

\section{The effect of bush setting on magic realism in Starbook}

Ben Okri's fantastical tale, Starbook (2007) is a classic story of love overcoming adversity. Though such themes are nothing new and are readily found in African literature, what is fresh is the form in which the story takes. In Starbook we have what I call an anchor setting. This is the setting through which all other settings spring - the foundation for all the other settings if you like. This anchor setting is in three forms: the first is that of the narrator through whose vision the story is told; the second anchor is the world of the prince as he goes through life in his father's surreal kingdom. The third anchor is that of the maiden's world characterised by the enchanted forest and artistry of its inhabitants. This third anchor, on a deeper level to that of the prince's, provides the foundation for the dream world since the fantastical is magnified and expanded over time and space. It is here that we learn the true meaning behind the maiden's father's mantra, "the deep can only come out of the deep" (Okri, 130).

The dream world of Okri's Starbook is devoid of the political upheavals common in satire, political commentary. Here the dream becomes a platform to feel things more richly, more powerfully than in the real world. For the characters dreaming is creation, it is life. It is a state in which the profound is experienced. A life without dreams or one in which dreams are not triggered is shallow and mundane. An example of this is the manner in which the Mamba's exploits are described. It is without doubt that he is a gifted wrestler and much feared. However, his actions "amazed the eye but not the vision. It did not set the masters dreaming" (Okri, 170). Through the dream world the characters immerse themselves in their surroundings and become profoundly affected when new information is revealed. Outside the dream world in the physical setting speculation is the order of the day. The maiden's father causes much speculation from the villagers; the maiden also speculates about her father's powers and abilities; the purpose behind the sculpture leads to intense speculation and in the process untold suffering; the progress of the maiden's own sculpture is also a topic of heated speculation; the prince speculates about the maiden, about women in general, about village life. Nothing seems to be clear and only entering the dream setting can reality become clear. Everything is made clear in the dream setting. In the words of Von Hendy "myth is seen as both the vehicle and the repository of permanent truth unavailable to mere rationality: a repository, if considered as a reward of past imaginative acts, a vehicle, if considered as the mythopoeic act itself" (149). The real world has conflicts and problems whereas the dream setting has solutions and alternatives. The exchange that the king has with the soothsayer after the latter remarks that only love can save the prince from his condition is a case in point.

'How do you know this?' asked the king. 
'I was directed to tell you this in a dream.'

'Who told you in your dream?'

'You told me in my dream,' said the soothsayer.

'Me?'

'Yes, you, the king.' (Okri, 251)

The setting of the real world is thus shown to be inadequate for one to fully experience knowledge in its pure infinite form. Faulkner states that "the physical details of the setting become linked with the values, ideals and attitudes of that place in different times. Setting can add an important dimension of meaning, reflecting character and embodying theme" (Faulkner, 70). The conversation the soothsayer has with the king shows how the physical setting may not always provide the answers we seek. The dreams achieve a unique sense of reality in that they enrich the character's existence. Dreams thus do not occupy the mind during sleep, they supplement physical experience and at times substitute one form of reality with another. The maiden's understanding of the three spirits shows how her understanding of her father's abilities is amplified from what she previously thought she knew. Her dreams change the reality she is used to and this new information enriches her immensely, "her father shone now in majestic splendour, his taut skin seeming to radiate a transferring light through the sweat of his brow and from his three eyes that shone so in the dark light of the workshop" (Okri,110).

In the dream setting the reference to time is vague and unspecific. In fact, the whole narrative in Starbook deliberately avoids specific reference to time that is important but subsidiary to issues within the plot. Things are allowed to run their course without the 'tyranny of time'. As such the pace of the novel is languid even though issues of sickness, impending calamity and anxiety are ever present. Perhaps what the dream setting emphasises is the need for reflection before action is taken. It must be said that this need for reflection is depicted by the narrator as superfluous at times and an excuse for slacking. The guardians are a prime example of this. However, the silence that the maiden has with her father after asking him if he employs spirits shows how time and space is elastic. The ensuing silence is one that is pregnant with experiences, reflection, projection, past and parallel lives: "many years passed before the silence was over. Many dreams. She had been raped by a slave-master across the seas; repeatedly, she endured it, at noon, when the house slept. She had borne three children to two slave-masters" (Okri,113). In that time also we are told that, "she had walked six hundred miles to join a colony of freed slaves" (Okri,113). At one level she is with her father. On a deeper level she is in a longer time zone experiencing horrific acts to her person. Thus, in her immediate reality with her father in the shed she is relaxed. Yet on a different reality set in the future she is in pain and in hardship. On a third level we see an expansion of the slave theme in which she is now traversing hundreds of miles in search of freedom. All these levels are realities in their own right. It is just that we see one reality merging with another in a totally unrelated context. The text is set in Africa but the setting has a viscous quality to it. The tribe of artists can conceivably be anywhere in Africa. Even the kingdom of the prince is vast and without clear boundaries. As Cooper states, "Okri's vision is that of an intellectual writer who has been exposed to the interpenetration of cultures in the global context." (283). It should be remembered that setting in magic realism exists in a tiered form and each level allows a character to grow and issues to achieve a universal appeal. The slave trade shows how all encompassing the dream setting can be. In the words of Welty, "Place is the crossroads of circumstances, the proving ground of what happened? Who's here? Who's coming? Setting is created by language" (53). A good way in which Welty's view can be put to the test is when the narrator describes how the kingdom is run. It is clear that the language used in the following description puts the dream world as the most ideal setting to deal with the challenges faced by the king.

"The kingdom was sprawling and vast and within it were many sub-kingdoms. In fact the kingdom was so extensive it did not know itself. And the king knew it only through the cartography of dreams" (Okri, 236). We are told that the king uses dreams to reach out to his subjects. "Time devoured the possibilities of ruling the immense kingdom, and space mocked the reforms, changes, edicts set forth; space distorted them on arrival. The only thing that time and space could not affect and distort, but would aid and enhance, was the way of ruling through dreams" (237). This is a setting in which everything dreams, even plants and birds in the forest.

The use of gaps, of dreams, of teleportation and transformation render our understanding of setting obsolete. In fact the traditional concept of setting is a hindrance to understanding the events that hold the characters together. Some of the characters are almost godlike or at par with the gods, yet oddly mortal and prone to anxiety. The maiden's father is one such example. He has the ability to command spirits to work on his statues which he ultimately transforms into human beings. We are told of the maiden's shock when her father commands the prince, who has become his apprentice, to arise from among the statues.

"She had always revered her father; now she was in utter awe of him. She no longer thought of him as being entirely human, but something more, which she dared not specify in her mind..." (Okri, 338). It is her father who creates a myth to sustain the memory of the tribe among future generations after the white spirits have decimated the population and its way of life.

All human activity has a purpose: to rebuild or reaffirm a particular idea. Idleness or the lack of purpose is nonexistent. All the characters have energy. However, it is the calm characters, those with an unflappable demeanour who thrive. The maiden, her parents, the prince and the king are the best examples of this. The maiden's father puts it well when he describes the prince's character to his wife. "Tranquillity in a man is an achievement, a discovery, almost a by-product of a great insight or illumination." (Okri, 341).

These characters succeed because they stay focused on their goals and avoid being distracted. The maiden, "learnt to stop seeing what she didn't want to see" (Okri, 303). Likewise the maiden's father when working in his workshop is so focused that he disassociates himself physically and spiritually from anything. Though the workshop is a form of anchor 
setting, within it the maiden's father is actually working outside it and outside his self. He is in another setting, working with spirits, creating new life among the mythical statues. He transports himself to another realm and "surrendered himself to its currents, and then found the gates to unsuspected worlds, where he made new friends and attended the convention of master spirits from all the worlds. While in his workshop he might as well have been dead" (Okri, 324). If one stops relying on sight to navigate through life, one stops contemplating setting as a fundamental part of existence. You choose to function on your own terms and not at the mercy of the people or things around you. Thus, the characters in Starbook seem to turn inwards to move forward with their lives.

Danow states that "magical realism's far reaching origin is perhaps rooted in the remembrance of childhood, with its attendant wonder at the splendour of the world, whose multitudinous variety of actual and potential manifestations within it engenders corresponding flights of the human imagination" (Danow, 70). It is clear that the oral tale and style with which Okri narrates his tale lends a sense of credence to the action of the plot. If the oral tale makes the reader more likely to be receptive to bizarre and mind-boggling experiences of the young prince, then it can be said that the lack of a fixed identity makes the story transcontinental. With the exception of the antagonists Chief Okadu and (to a lesser extent) the Mamba, none of the major characters have names that pin them to a particular setting. The king, the prince, the maiden and the rest are identified by occupation rather than location. As such the characters achieve a 'linguistic' freedom that compliments their movements across space and time. This lack of names contributes towards making the characters invisible and yet simultaneously accessible to the reader. This is particularly evident amongst the masters of the tribe of artists. The identity of the masters and of the spirits who visit them at council is secondary to the function behind the interaction - that all things are linked, 'Sometimes a trio of such interstellar beings, radiant in lights of gold and blue, with eyes of shining stones, and bodies wholly transparent, would tell the masters of the way of their civilisations and how they came to an end. They would tell of how they now wander the universe, seeking a familiar air and space in which to leave their tale as a guide and warning to those of future ages...'(Okri, 136).

All through these revelations, these interactions with the mythical and the absurd, the medium of dreams firmly asserts itself as the new setting. Dreams are portrayed as the most intense and fulfilling plane which paradoxically hinder and propel an individual to heights far beyond what can be achieved in a physical setting. Dreams thus come to symbolise purity, wisdom, angst, madness and even a dose of irrationality amongst the characters. These dreams need not be detached from reality. They do in fact anchor themselves in some form of reality. For instance, we are told that for the maiden "the river became her dream" (Okri,160) and that her "father's workshop was rich with dreams" (Okri,105). Dreams are the life and soul of the tribe of artists and the maiden's father puts it succinctly when he says, "without new dreams we will surely die" (149). Dreams then, in terms of the revelations they provide and in terms of facilitating interaction between characters, become a new kind of setting. Setting moves beyond the here and now to reside outside the boundaries of space and time, achieving a fluidity and intensity not easily observed in many aspects of written African literature. Gaylard maintains that "the imagination is very often defined in terms of its relationship to reality and usually it is defined as different from, even opposed to reality" (2). Indeed what we see in Starbook is that while the characters are living in their reality, their lives are nothing short of robotic, lacking any spark or vibrancy. The maiden and the prince acknowledge their reality but find no peace in it. The prince, for instance, torments the wise men with questions about life showing an unease with which he relates to his surroundings. It is only when he is initiated into the mysteries of women and given insight into his mother through dreams (that are themselves staggered into different levels) does he become transformed. "The prince awoke the next day a different person, but he didn't know how he was different. He felt he had developed an extra faculty, another head, or that his eyes saw things he had never seen or noticed before, as if on loan from the spirits. The world was new to him, and yet ancient and familiar" (Okri, 32). The dream world is a powerful entity and given that the prince and the maiden meet first through dreams when the maiden is undergoing her own initiation, we see that dreams can also harbour promise and hope other than fear and foreboding.

In Starbook, the characters do get sick but it is unlike what happens in Maru. The prince is bedridden for days but his infirmity is not of the body but of the soul. In fact the prince's condition reveals that even in the anchor setting we see a setting within a setting made possible through dreams. The prince's sickness is so severe that the herbalists attempt to cure him by moving away from the physical setting into another realm. "The herbalists even found their way into his dreams and attempted to do battle with the shadow forms that lurked in the prince's mind" (Okri,56). The Mamba is also prone to attacks but these are more a consequence of the 'second sight' and the forest's intervention rather than anything physical. In the dream setting time becomes of little help to understanding the challenges and experiences of the characters. For instance, there is a scene where the prince falls into the abyss while a statue of the maiden's father. Here we see the type of mythical exaggeration similar to John Milton's Paradise Lost when Satan fell after being banished from heaven. In Okri's description, the prince's fall is not a fall of doom. It is rather a fall of revelation, of understanding just how minute man is in the infinite void. The fall, "took him beyond nightmare, beyond chaos, beyond madness, beyond death even...he fell through the dark secrets of the universe, through all the versions of lives and dreams and deaths of all beings, in all the universes, whether of humans, animals or plants, or creatures from realms unthinkable" (Okri, 336).

What needs to be understood is that when one talks of a setting of emptiness it means that the setting has no tangible quality to it, what one sees are forms of nature, mere representations. These are influenced by and in turn influence the characters in the story. This is evident in the forest. The manner in which the maiden, the prince and the Mamba relate to it shows how pliable this supposedly physical entity is. For instance, when the characters transform or undertake a particular action, the forest also reacts to this. Though the forest is self contained (it has its own spirits, fairies, animals and energy) it can merge with the will of the character. Simola puts it well when she states, "rivers, roads and hunger are major metaphors in Okri's later novels," (403) and in Starbook the relationship that the maiden and her companions 
have with the river is a case in point. The prince from his place of concealment observes the following: "the seven maidens appeared from out of the river, attired in splendid white robes...the maidens, with hands linked danced on the surface of the river, laughing and singing" (22). If a maiden levitates the water upon which she dances is able to support her. This then is the natural outcome of the fantastic. The setting bends to the whim of the character. It does not define the character but accedes to the mannerism with little or no resistance. This does not mean that the setting is not hostile or protective. The Mamba's efforts to get close to the maiden in the forest are met with defeat, frustration and pain. The setting thus can take on a life of its own and though it is in theory a physical reality in which the characters interact and discover the world around them, the forest appears to be an extension of the psyche of the characters. When the Mamba sees the maiden's dancing and levitating one feels that his reaction is due to the protective manner of the forest acting in the best interests of the maiden. "The Mamba fell down in terror and astonishment at this sight, and when he got up he found himself partially blinded" (Okri,183). In all his activities in the forest, the Mamba is never welcome in the forest. He touches a plant that the maiden touches and it dies. When he follows the prince who has morphed into an antelope the sight of the beautiful animal blinds him for a second time.

\section{Conclusion}

This paper has sought to argue that though magic realism can take several forms it is when it stems from that bush setting made popular by oral tradition that it is able to evolve into a more advanced version of itself. It has shown how Maru uses magic realism without the background of the local oral literature. This lack of folklore means that the author has had to use a different canvass, that of the mind, in order to display the fantastic. The shortcoming of this is that it severely restricts how the magic realism can perform as it was. Starbook shows how the oral tradition allows for the magic realism to reach aspects such as the dream setting which cannot be possible in texts that circumvent the oral tradition. The use of the mind as an alternative setting for fantasy that writers use to augment the lack of the bush setting has its limitations. Maru shows how the form of magic realism cannot expand on its type of setting unlike what is seen in Starbook. The fusion of myth with reality using the bush setting enables the readers (or listeners) to be exposed to stories within stories all with the ability to telescope into one another.

\section{References}

Anderson, E. D. (2010). "Yesterday, Today and Tomorrow: Socio-Cultural Evolution in African Literature and Film". Mosaic African Studies.Vol. 1,1-10.

Ashcroft, B., Griffins, G., and Tiffin, H. (1989). The Empire Writes Back: Theory and Practice in Post Colonial Literatures. London: Routledge

Barhoun, B. (2013). "Post Colonial Discourse: magic, the carnivalesque and hybridity in Ben Okri's Abiku Triology."Phd thesis. University of MadridBoccia, M. (1994). "Magical Realism: the Multicultural Literature." Popular Culture Review 5.2, 21-31

Cooper, B. (2006). "Landscapes, Forests and Borders within the West African Global Village, Mapping the Sacred: Religion, Geography and Post Colonial Literatures. Ed. Paul Simpson-Housley and Jamie S. Scott. Amsterdam: RodopiCooper, B. (1998). Magical Realism in West African Fiction: Seeing with a Third Eye. London: Routledge

Danow, D. (2004). The Spirit of Carnival: Magical Realism and the Grotesque. Lexington: University Press of Kentucky

Eileen, J. (1992). African Novels and the Question of Orality. Indianapolis: Indiana University Press

Faulkner, C. (2004). Introduction to Different Literatures in the World. New York: McGrawhill

Gaylard G. (2005). After Colonialism: Africa Postmodernism and Magical Realism. Johannesburg: Wits University Press.

Handeland, L. (2000). Components of a novel. London: Oxford University Press

Hawthorn, J. (2005). Studying the Novel. London: Oxford University Press

Head, B. (1971). Maru. Johannesburg: Heinemann

Irele, I. (2001). The African Imagination: literature in Africa and the Black Diaspora. Oxford: Oxford University Press Jackson, R. (1981). Fantasy: The Literature of Subversion. London: Methuen

Joseph, D.S. John, P.T. (1998). The Study of Language and Literature. New York: Harcourt Brace

Lindfors, B. (2010). Early West African Writers, Amos Tutuola, Cyprian Ekwensi and Ayi Kwei Armah. Asmara:

Africa World Press

Newell, S. (2006). West African Literatures, Ways of Reading. Oxford: Oxford University Press

Okri, B. (1991). The Famished Road. London: Vintage

... (2007). Starbook. London: Rider

Rooney, C. (2000). African Literature, Animism and Politics. London: Routledge

Simola, R. (2002). "Immigrant Stories of belonging by Ben Okri." African Writers and their Readers: essays in honor of Bernth Lindfors. Ed. Toyin Falola and Barbara Harlow. Trenton: Africa World Press, 397-413

Tutuola, A. (1952). The Palm Wine Drinkard. London: Faber and Faber

Von Hendy, A. (1993). "The Modernist Contribution to the Construction of Myth." Modern Myths. Ed. David Bevan. Amsterdam: Rodopi

Welty, E. (2001). The Study of Literature. London: Oxford University Press

Wimsatt, W.K. (1946). Beardsley, M.C. “The Intentional Fallacy,” Sewanee Review 54.3, 468-88.

Woods, T. (2007). African Pasts, Memory and history in African Literatures. Manchester: Manchester University Press 